\title{
Education of Students with Disabilities in the USA: Is Inclusion the Answer?
}

\author{
Myung-sook Koh \\ Eastern Michigan University \\ Michigan, USA \\ Sunwoo Shin \\ Oakland University \\ Michigan, USA
}

\begin{abstract}
American society has continued to question what the most appropriate way is to educate students with disabilities. Whether teaching students with and without disabilities in the same classroom is a best practice has become the most controversial topic in education. The present study attempted to examine the present state of inclusive education through a comprehensive review of the literature from 30 years of practice and current teacher preparation programs. Results showed that although quantitative physical inclusion in the United States has doubled, new general education teachers were not prepared enough to teach students with disabilities confidently and have held the similar perceptions, concerns, and perceived barriers regarding the success of inclusion to the ones since the beginning of the inclusion movement. Accountability for the academic and social success in the inclusive classroom did not result in a more effective system than the dual educational systems of general education and special education.
\end{abstract}

Keywords: Inclusion; inclusive education; teacher preparation; perceptions of inclusion; elementary teachers

\section{Introduction}

While holding common concerns in the rapid inclusion movement of students with disabilities, inclusion practice has gained popularity while gathering feasibility over the last 30 years. Various supporting models, inclusion designs, and educational strategies involving the curriculum, staffing, instruction, accommodation, and modification have been designed and implemented to make classrooms more inclusive as well as more appropriate learning environments for students with and without disabilities (Cronis \& Ellis, 2001; Shogren, Gross, \& Forber-Pratt, 2015; Walther-Thomas, Bryant, \& Land, 1996). For example, special education positions have changed to include a teacher 
consultant position, with enriched and advanced educational and assistive technology being developed and used for instruction, functional skills, and communications. Even special education related documents and forms have become available in electronic forms, in order to reduce time involved in writing an Individualized Education Program (IEP).

The key question is, then, what is the results of these changes? How has inclusive education in the United States progressed toward providing the best education to both students with and without disabilities? Are the changes and efforts to improve inclusive education over the past three decades effective? Is the education of students with disabilities in a general education setting working for all involved? Is the inclusion movement now supported by empirical evidence?

\section{Obtaining a Right for Public Education}

Since 1975, American society has continued to question what the most appropriate way is to educate students with disabilities. Consequently, the educational system has undertaken multiple reforms over the last 30 to 40 years (Ross-Hill, 2009). The civil rights movement and the Education for All Handicapped Children Act of 1975 (PL 94-142) affected every school in the country and have resulted in public schools opening their doors for students with disabilities. Under this law, a federal list of educational disabilities was identified and used to qualify the students to receive special education services. In addition, the "least restrictive environment (LRE)" and "appropriate" education pushed public schools to provide "a continuum of special education services" to students with disabilities. Consequently, professionals and parents could choose the most appropriate educational settings for their students' best educational opportunities.

These revolutions required changing the roles of general and special educators, school administrators, parents, and others involved in the educational process. Training of special education teachers (versus general education teachers) began as a requirement for those teachers who would become case managers of educational programs of identified students with disabilities (Heward, 2012; Shogren, Gross, \& Forber-Pratt, 2015).

\section{Questioning about the Receiving Specialized Education}

The goals identified in PL 94-142, however, came up against another educational perspective in 1982, as a result of the publication of A Nation At Risk (U.S. Department of Education, 1982), which resulted in a widespread call for a systematic reform of schools. The debates on Regular Education Initiative (REI), the "full" inclusion movement, had its beginnings during this restructuring period and resulted in an increasing number of students with disabilities "moving back" into general education classrooms, ultimately calling for general education teachers to be more responsible for the education of students with disabilities (Ainscow, 1997; Cagran \& Schmidt, 2011; Patton \& Edgar, 2002). 


\section{Two Perspectives on "Appropriate" Education}

Interpretations of the Individuals with Disabilities Education Act (IDEA) mandatory regulations and the 1980s's REI reform movement sparked ceaseless debates on what the best educational services for students with disabilities are, in order to guarantee their rights and privileges for an education (Heward, 2012). These debates included two perspectives for LRE. Full inclusion proponents believed that educating students with disabilities in special education settings or apart from their typically achieving peers limited their rights to public education and was therefore a type of "segregation" (Eitle, 2002). Full inclusion opponents believed that special education settings and supports, like the continuum of special education services, could provide a free "appropriate" public education for students with disabilities who need unique supports and educational delivery (Fuchs \& Fuchs, 1994). The inclusion proponents hold that LRE is a mandatory regulation requiring that students with disabilities not be segregated from general society and general education classrooms, in the interest of "human rights." The opponents of the full inclusion movement question how best to address the human rights of the students with disabilities including their rights to a free and "appropriate" public education. Placing students with disabilities in a general education setting with the same teacher, curriculum, and standard regardless of the nature and severity of their disability and difficulty is not sufficient support for their educational needs. Teaching all students in heterogeneous classroom does not address the rationale of offering a continuum of special education services: students with disabilities were referred for special education due to their inability to learn in general education classrooms (Farrell, 2000; Ferri \& Connor, 2005; Ruijs \& Peetsma, 2009).

How have these two perspectives (full inclusion vs. continuum of services) used empirical evidence of the effects on students to defend their interpretations? Inclusion proponents have insisted that students with disabilities would learn better academically and socially in general education classroom. Socially, students with and without disabilities would experience more balanced friendships in the inclusive settings, and academically, students with disabilities would acquire more academic knowledge through the effective general education teacher instruction because general education teachers were the ones certified to teach academics (Grider, 1995; Hartzell, Liaupsin, Gann, \& Clem, 2015; Hunt, Farron-Davis, Beckstead, Curtis, \& Goetz, 1994; Mather \& Robers, 1994). In other words, inclusion proponents believed that general education settings were the best educational setting to provide "appropriate education" to students both with and without disabilities. The opponents, however, provided evidence that almost $90 \%$ of the students with disabilities were identified as needing special education in schools after earning learning deficiencies in the general education classrooms. Returning these students to a general education setting means they were going back to failed educational settings without hands-on system or structure (Farrell, 2000; Fuchs \& Fuchs, 1994; Grider, 1995; Ruijs \& Peetsma, 2009). After 30 years, the debate continues, unresolved still today in the field of education in the United States. 


\section{Quantitative Practice of Inclusion Since 1986}

Without any resolution of these controversial debates regarding the best service delivery model for educating students with disabilities, the national prevalence statistics from the NCES showed that over the course of a 22-year period (19882014), the practice of inclusion for students with disabilities, age 6-21, who received education in general education settings for at least $80 \%$ or more of school day (not $100 \%$ full day, but $20 \%$ may be for related services) in the U.S. has doubled (from $31.7 \%$ to $62.2 \%$ ). Figure 1 shows the percentages and a line graph denoting the progress of the number of students being included (National Center for Education Statistics, 2017).

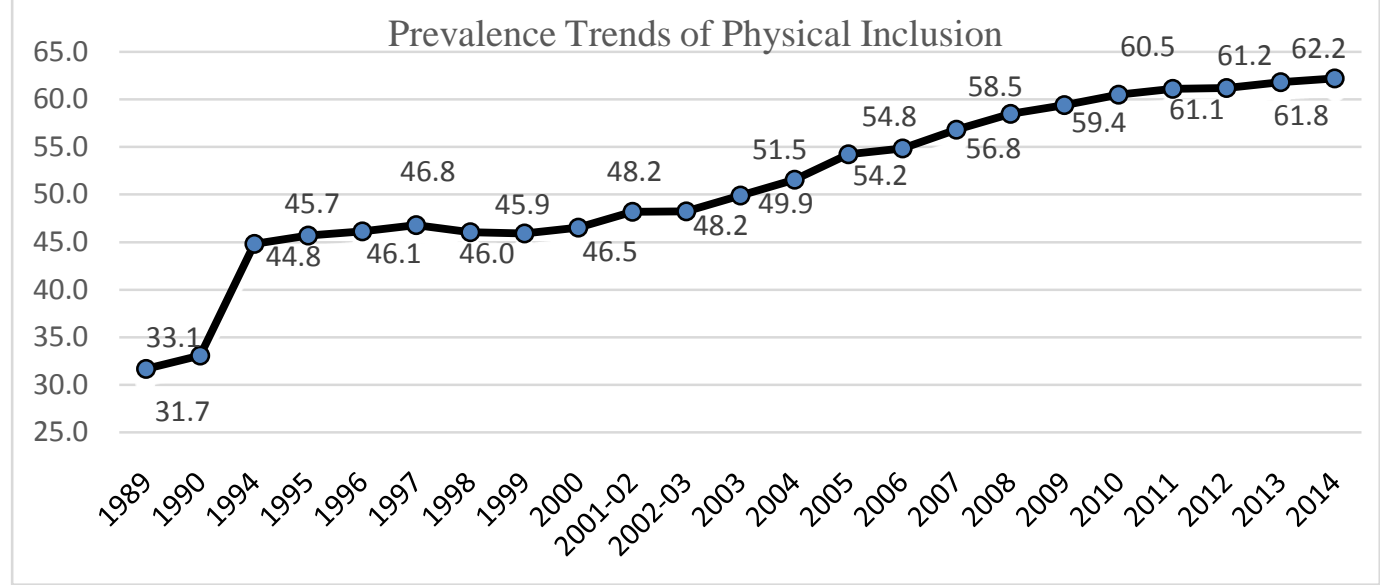

Figure 1. The Percentage of students aged 6 through 21 served under IDEA educated in the general education classrooms more than $80 \%$ of school time.

Additional statistics from the NCES website showed this information on prevalence trends disaggregated by primary educational disabilities. As seen in Figure 2, there was an increase in the education of students with disabilities in inclusive education across each disability category. For example, students with speech/language impairment (SLI) were educated in inclusive settings more than any other disability area, although over time, the total percentage decreased by $1 \%$. All disabilities increased their instructional time in general education settings, especially students with autism (113\% increase) and deafblindness (98\% increase), followed by emotional disability (73\% increase), TBI (63\%), OHI (53\%), and specific learning disability (SLD, 51\%). On average, national statistics showed that only one disability (SLI) area ranked at the 50\% level of their education being in inclusive settings for $80-100 \%$ of the school day in 1988, increasing to six (almost seven) of 12 disability areas ranked at that level by 2011. Surprisingly, students with learning disabilities, the disability with the highest incidence and strongly related to academic learning deficits, were not educated in inclusive settings as much as those students with speech/language impairments. There was no data available specifically for students with mild intellectual disability separate from those with moderate/severe/profound intellectual disabilities, although students with mild intellectual disabilities comprise more than $85 \%$ of the entire intellectual disability category, and academic areas are typically their main school concerns resulting in IEP goals and objectives. 


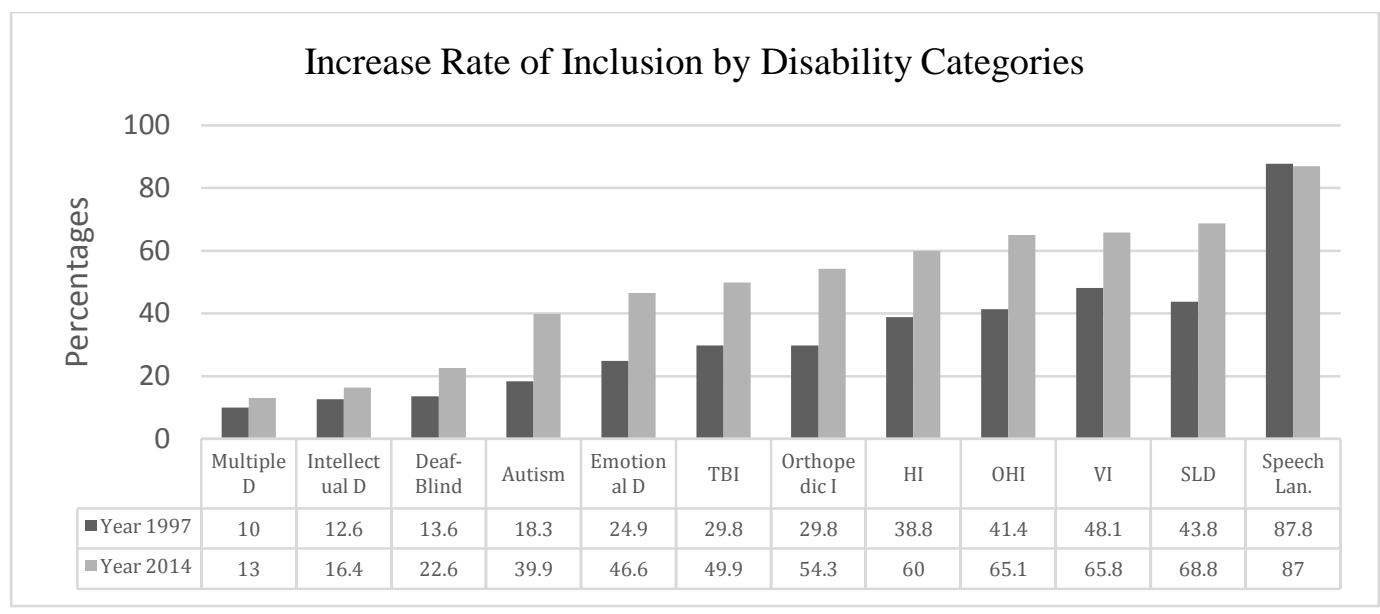

Figure 2. Percentage of students ages 6 through 21 served under idea, part b, by educational environment, year and disability category: Fall 1997 and fall 2014.

\section{Common Concerns}

As a result of the varying perspectives for best practice in teaching students with disabilities, there have been vague roles for general education and special education teachers, and insufficient planning and preparation to support the needs of students with disabilities involved in the inclusion movement (Dorn \& Fuchs, 1996; Kauffman \& Smucker, 1995; Will, 1986). With more inclusion of students with disabilities, their education in general education settings predominantly fell to general education teachers. In the mid 1980's when the REI began in the United States, both proponents and opponents of inclusion movements shared a common concern about the general educational system not being prepared to meet the diverse educational needs of students with disabilities and to remediate their learning deficiencies, especially general education teachers. The major concern was whether or not general education teachers were prepared for successful inclusive education, because successful inclusion necessitates highly qualified teachers who were ready to meet the needs of exceptional learners (Allday, Neilsen-Gatti, \& Hudson, 2013; Harvey, Yssel, Bauserman, \& Merbler, 2010; Smith, Polloway, Patton, \& Dowdy, 2012; Thompkins \& Deloney, 1995).

The purpose of this study is, therefore, to investigate how much inclusive education has progressed toward the goal of providing the best education to students with disabilities. Specifically, is inclusive education working overall for the education of students with disabilities? This question will be addressed by investigating these three important questions: 1) Are general education teachers well trained to handle the additional responsibilities of teaching in classrooms with increasing numbers of students with disabilities? 2) Are the perceptions of general education teachers positive and supportive towards their students with diverse needs, and have their concerns lessened or subsided? 3) Are there measureable academic and social outcomes that demonstrate the success of students being educated in inclusive classrooms? 


\section{Method}

\section{Search Procedure of Literatures and Teacher Preparation Programs}

The focus of the extensive literature review conducted for this study included identifying research and statistics in three key areas. The results were aimed to draw conclusions as to the success of the inclusive education over the past 30 years.

For question one, an online review of current teacher preparation programs in all 50 of the United States was conducted. The data was collected and analyzed in the following sequence. First, using the National Council for Accreditation of Teacher Education (NCATE) website, the list of NCATE accredited university/college names were selected and sorted by states. Second, these university/college names, each were then searched to identify colleges of education, undergraduate programs (graduate programs were looked at when they were the only ones), majors, teacher education, and elementary education. Third, from the teacher education and elementary education programs, program requirements, required courses, plans of study, student handbooks, and university catalogs; course requirements/descriptions were reviewed including prefix and course numbers, the title of courses, credit hours, and field experience requirements. Some programs did not have clear course prefixes, describing whether or not it was a special education course, so an extended search for confirmation was needed. Fourth, information from evaluated programs was sorted using qualitative categories of perceived level of preparation, labeled as: None, basic, and more complete (more than two courses including method courses). The authors reviewed only elementary programs for initial certifications because they were the main teacher preparation programs and were more comprehensive than secondary level programs that needed to be searched by specific subject areas and in addition, may have different special education course requirements by subject area. Although the time involved in this comprehensive website review was intensive (10 to 50 minutes per university/college to find listed information), this information was essential for a complete understanding of teacher preparation programs in the United States and specifically of special education training within general education teaching.

For questions two and three, comprehensive literature reviews of peer-reviewed journals were conducted using ERIC as the research tool with no-restricted dates. For question two (teacher perceptions and concerns regarding inclusive teaching), the database was searched using the key words of 'inclusion' and 'perception,' and for question three (measurable success of academic and/or social inclusion), the search was conducted using the keywords 'inclusion' as a document title and 'academic' or 'social' within the articles. The articles were then filtered while focusing on in-service (not pre-service) teachers, grades PreK$12^{\text {th }}$, and research sited in the United States only.

The results for question two were then sorted in a qualitative manner, based upon the independent interpretation of each author, using the following labels: positive, negative, or mixed perceptions about inclusion. The articles were sorted as positive when the perspective of teachers within the article was supportive of the inclusion effort, negative when they were not. The category of 
"mixed" was used when the teachers supported the concept of inclusion but also identified a list of concerns, barriers, or conditions. It was sometimes difficult to determine whether the study results should be classified as having either positive or negative results, because both perspectives were offered. An example of these cases, teachers might have been responding positive for mild disabilities but negative for severe disabilities.

For question three, the number of studies and results (gains, no difference/decreased, or mixed) were sorted by decade (three groups: 1986-1995, 1996-2005, and 2006 to current) to look for changes over time and by quantitative/measurable evidence. Only literature published after 1986 was selected because prior to this, inclusive education was not actively practiced and not officially on-debates for the efficacy of inclusive education yet. Also, studies on this topic were not active before then. In addition, students of disability rates consisting of the total enrollment were reviewed to see the prevalent trends of students with disabilities as well as high incidence disabilities during the inclusion movement periods.

\section{Results}

The present study examined the 30-year practice of inclusive education. Approximately 225 elementary teacher preparation programs in 50 states were reviewed and 158 peer-reviewed articles were identified and examined in order to answer the three research questions.

\section{Question 1: Teacher Preparation State}

General education teacher training and preparation for teaching in an inclusive classroom is undoubtedly a critical factor for successful inclusive education (McCray \& McHatton, 2011). There was no pre-data available to compare how general education teacher preparation programs have trained teacher candidates for inclusive education each decade. The current review of 225 elementary teacher preparation programs encompassing all 50 states, found that approximately $15 \%$ (34 programs) of the universities did not include any special education course in their programs, approximately 62\% (140 programs) of the universities required one introduction to special education course and 3\% (7) of the programs offered only elementary and special education combined majors without a separate elementary program. The table 1 shows the summary of the national teacher preparation status.

Table 1

Comparison of Elementary Teacher Preparation Programs with Special Education Courses $(\mathrm{N}=\mathbf{2 2 5})$

\begin{tabular}{llll}
\hline SPED Courses & None & Intro. to SPED & Two or more courses \\
& $15 \%$ & $62 \%$ & $19.5 \%$ \\
\hline Course Credits & 2 credits & 3 credits & 4 credits \\
& $7 \%$ & $82 \%$ & $4 \%$ \\
\hline Field Experiences & None & Required & Exact hours or credits \\
& $62 \%$ & $30 \%$ & $18 \%$ \\
\hline
\end{tabular}


Classroom/behavior management courses were not counted as a special education course, because most universities offered it as a non-special education course.

The number of credit hours for the special education courses and the field experience requirements were checked as an indicator of how rigorous the special education courses were. Among 218 special education courses offered by 191 programs (34 had no courses), the majority of programs offered three-credit special education courses. Approximately $21 \%$ (48 programs) of the programs offered unique major/minor programs, such as elementary and special education double endorsements, special education concentration, or minor programs. Among those 48 elementary and special education dual programs, 41 programs offered two options: only elementary major or the elementary and special education combined major. In these 41 two-option programs, elementary only programs did not require any special education courses. Some programs offered special education as a supplemental component in their elementary major such as a no-licensing-based add-on to the elementary majors with 12 to 20 extra special education credit-hour requirements. In these programs, special education was one of the options the candidates could choose amongst three or four other areas such as English Language Learners (ELL), extracurricular subjects, etc. Some programs made supplemental add-on programs as mandatory for the elementary majors and some offered it as an option. The fiveto six-year combined undergraduate and master program majoring elementary and special education did not have separate elementary or special education licensing programs, nor the undergraduate or graduate only degree programs.

Among 225 programs, approximately 30\% (68 programs) required some form of field experiences in special education settings and 62\% (143 programs) did not mention it in the course descriptions. Among 68 programs requiring field experiences, only $61 \%$ (41 programs) clearly required exact field hours (40 minutes to 40 hours) or one credit lab/course hour, but $39 \%$ stated that 'field experience may be required.' Among the required field hours, 10, 15, and 20 hours were the most frequently required hours in the course descriptions.

\section{Question 2: Perception Trends of Teachers Regarding Inclusion}

Results of 86-literature review from 1970s to current were sorted by decades and then by positive, negative, and mixed feelings. Mild disabilities and learning disabilities were addressed most often in the studies as the target population. A majority of these perception studies focused on the participants' feelings on "the general concept or principle of inclusion." While reviewing the literatures, the following points were identified by the authors regarding how professionals perceive the meaning of inclusion. First, some studies differentiated between the teachers' perceptions on the general concept of inclusion and their willingness to teach in an inclusive classroom; the participants' responses showed ambivalence where they supported the concept of inclusion but were not willing to teach in such settings because of the listed concerns and barriers. Second, some studies demonstrated discrepancies between the teachers' support and self-confidence in terms of their knowledge on how to teach diverse learners and their actual teaching in inclusive classrooms. Third, the teachers' length of teaching experiences or previous inclusive teaching experiences did not impact their 
positive perception, but their special education backgrounds positively impacted their willingness to teach in inclusive classrooms. More experienced teachers supported inclusion less, but those who came from stronger special education backgrounds were more supportive of inclusion.

Overall, $14 \%$ of the studies concluded their participants supported inclusion, $62 \%$ were against, and $24 \%$ had mixed feelings about it. Figure 3 demonstrates the trends of teachers' perceptions regarding inclusion in each decade.

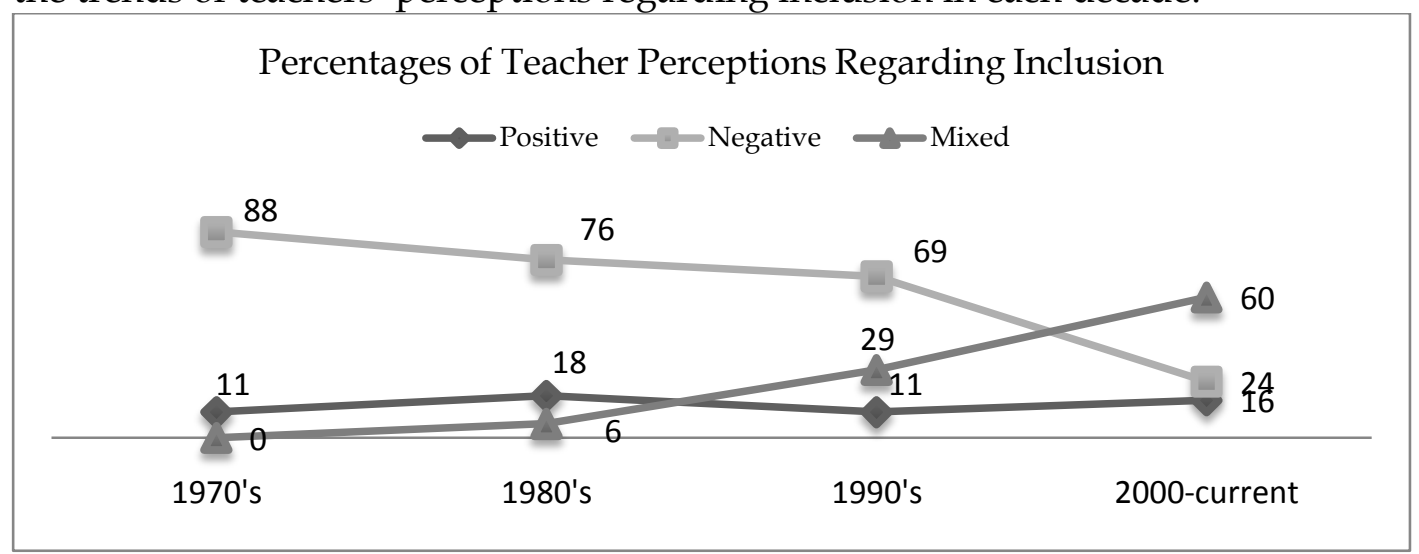

Figure 3. The percent of teachers' perceptions on inclusion between 1970 and 2014.

In the 1970s, a majority ( $88 \%$ ) of teachers voiced negative feelings about the inclusion, but it has gradually changed to mixed feelings $(60 \%)$ in recent years while the negative feelings have dropped to $24 \%$. Overall, after the 1990 's, it would appear that teacher perceptions of inclusion began to improve, which continued into the recent years and the decreasing negative feelings may have influenced the increase in teachers with more mixed feelings. Interestingly, teacher perceptions that are positive about teaching in inclusive settings have remained low, at less than $20 \%$ over the entire four-decade period.

Teacher-perceived barriers and concerns to effective inclusion. Although the results of this literature review showed less negative and more mixed feelings regarding inclusion in recent years, it also showed that the factors contributing to the teachers' ability to teach students with and without disabilities in inclusive settings have not changed over the last 30 years. Even the most recent studies (Cameron \& Cook, 2007; Kilanowski-press, Foote, \& Rinaldo, 2010; Logan \& Wimer, 2013; Muccio, Kidd, White, \& Burns, 2014) disclosed that several impeding factors played a part in participants' mixed feelings about inclusion. In other words, the same barriers and concerns to effective inclusive education were listed throughout the 40 -year inclusion practices.

Among 86 studies, 44 studies clearly included barriers and concerns, either as the main focus of the study or as add-on results. The most frequently mentioned barriers and concerns throughout time periods were inadequate and insufficient training to help teach in inclusive classrooms and lack of resources available for effective inclusive education from the early decades to current. Lack of planning time and class size are other demands for teachers that affect their feelings about inclusion. The adequate training needs were mostly focused on how to adapt and modify curriculum, teaching materials, and programs, to collaborate with special education teachers and multidisciplinary team members, to assess 
academic progress and interpret evaluation results, to manage behavior problems, to write behavioral objectives and IEP, to lead IEP conferences, etc. General education teachers were found to prefer co-teaching with special education teachers in their classrooms than collaborating with teacher consultants.

\section{Question 3: Accountability of Inclusive Education: Academic and Social Outcomes}

From 1986 to 2014, 72 studies were reviewed and sorted by publication decades, 40 focused on academic outcomes and 32 on social outcomes. A majority of studies on both study topics (approximately $88 \%$ of 40 on academic outcomes and $81 \%$ of 32 on social outcomes) were published in the first two decades (19862005). Although this might still allow for good pre- and post- comparisons, an imbalance of the quantity of studies in recent years (2006 to 2014) did not lend itself to such comparisons.

Academic outcomes of inclusive education. Among 40 peer-reviewed studies on academic outcomes, a little less than $50 \%$ utilized standardized measures involving pre- and post-testing before and after inclusion practices. Approximately $28 \%$ used self-reported data, such as interviews, surveys, etc., and another $28 \%$ used existing records such as state-wide test results, report cards, graduation rates, referral rates, etc. Some studies utilized more than two measures.

Given the limitations in comparing the results of these studies comparing the academic outcomes of inclusive education for students with disabilities, the reported outcomes find that approximately $20 \%$ of the studies (8 studies) showed evidence of academic gains, approximately 48\% (19 studies) found no difference or a decrease in academic scores, and approximately 32\% (13 studies) showed mixed results.

The comparisons made in these 40 studies varied. Most of the studies (68\%) investigated the academic outcomes of inclusive classrooms (no particular inclusion models or strategies were specified), which may be able to be compared with non-inclusive general education classrooms and/or special education settings (resource rooms or self-contained classrooms). Approximately $40 \%$ of the studies focused mainly on the academic achievement of students with mild disabilities and learning disabilities in inclusive classrooms, and the results with overall $20 \%$ gains were not encouraging. Approximately $33 \%$ of the studies compared academic outcomes of students with disabilities and typically achieving students. These studies showed varied results, such as comparing the outcomes of students with learning disabilities with low achieving general education students. The results of that study found students with learning disabilities gained academic skills, but not the lowachieving students. Another inclusion study compared the academic outcomes of students with learning disabilities, low, middle, and high achievers. The example results were that students with learning disabilities and high achievers demonstrated progress, but not low or average achievers. The typical studies were measuring reading, math, spelling, and writing achievements of students with mild or learning disabilities and typically achieving students in low, 
middle, and high academic levels. Only $10 \%$ of the studies had typically achieving students as subjects and measured whether including students with moderate/severe disabilities negatively impacted typically achieving students' academic achievements or academic behaviors. The results of these studies found that there was no negative impact on academic learning when students with moderate/severe disabilities were included. Approximately $32 \%$ of the studies on academic outcomes were focused on measuring the efficacies of specific inclusion models, evaluating the inclusion process, or strategies, such as Welsh Inclusion Models which measured the results of intensive year-long professional development on how to implement inclusive education through academic outcomes of students with disabilities and typically achieving students.

Social outcomes of inclusive education. Among 32 studies on the social outcomes of inclusive education, approximately $41 \%$ (13) of the studies found inclusion was effective in promoting social skills and growth, while approximately $25 \%$ (8) did not demonstrate growth, and approximately $34 \%$ (11) showed mixed results for students' social skills changing as a result of inclusion. Approximately $31 \%$ of studies focused on the social skill improvement of students with mild and learning disabilities while only $15 \%$ had severe/moderate disabilities as subjects. The remaining studies did not indicate specific disability areas but rather, general disabilities. Approximately 31\% included typically achieving students. Approximately $72 \%$ of the studies utilized self-reported data based on surveys or interviews, only $9 \%$ of the studies used standardized measures using pre- and post-testing, and about $34 \%$ used data from direct observations on the growth and gains of peer interactions and contacts, friendships, social acceptances using commercial-based checklist or researcher developed rating scales and sociometric measures like peernominations. Only $19 \%$ of studies examined the efficacy of specific inclusion models or evaluated how the inclusion process on social aspects was conducted, which usually was through testimonial type of narrative.

In summary, the extensive research review designed to show whether the trend towards more inclusive education over the last three decades has resulted in improved learning and social skills finds inconclusive results. Figure 4 shows a comparison of the academic and social outcomes of inclusive education from the literature identified across the last 28 years.

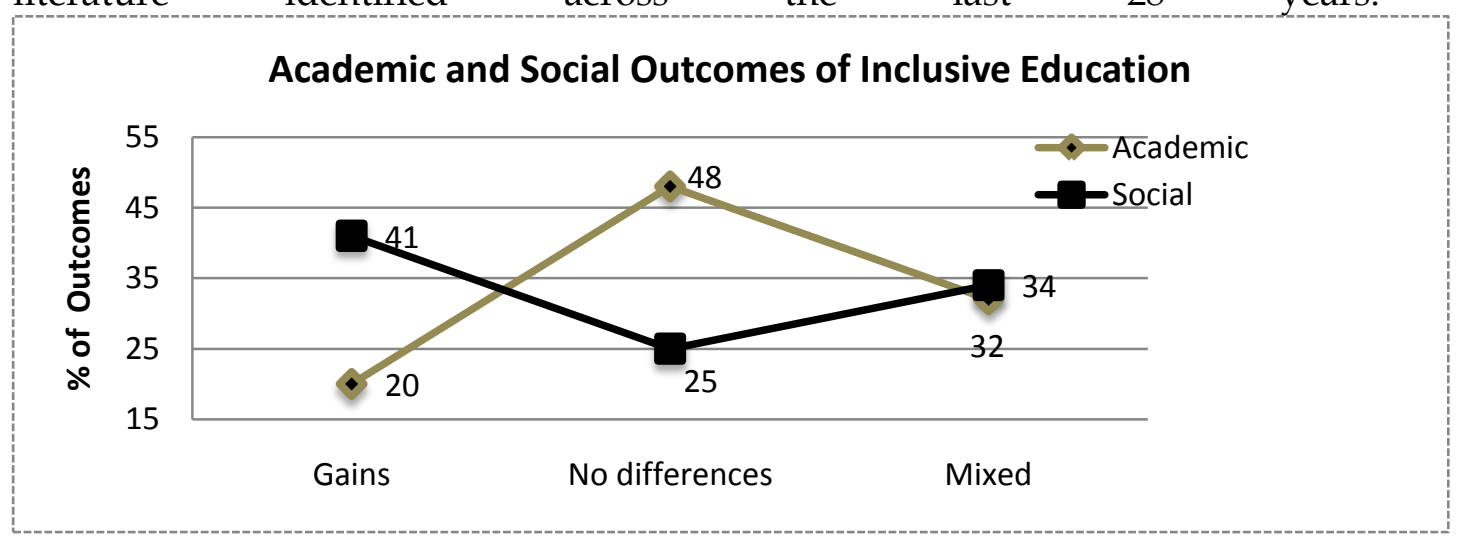

Feature 4. Academic and social outcomes of inclusive education from 1986 to 2014 


\section{Discussion}

The number of students with disabilities being educated in general education settings for at least $80 \%$ of the school day has almost doubled since 1988 . Is this effort to teach atypically achieving students with typically achieving students working in the United States? The intent of the current study was to investigate how much inclusive education has progressed toward the goal of providing the best possible education to students with and without disabilities. To answer this question, the study investigated three critical facts regarding the inclusive education: The teacher preparation status for inclusive education, teacher perceptions and any progress of their perceptions regarding inclusive teaching during the 30-year inclusive practices, and academic and social outcomes of students with disabilities.

When PL 94-142 was enacted in 1975 to address the education of students with disabilities, there was a sudden need to train special education teachers, requiring at least a Bachelor's degree with specific training for teaching students with particular disabilities. However, in the mid 1980's, when the REI was initiated, which required general education teachers to take more responsibility for educating students with disabilities, there was no national effort to mandate special coursework or certification to prepare general education teacher candidates for their future teaching students with educational deficiencies and behavioral issues. In fact, this study found that by 2014, there has been no mandatory changes of general education teacher preparation programs to address the increasing need for teaching academically and behaviorally diverse students, although the number of these students has been doubled in general education classrooms. The alarming findings are that the majority (77\%) of elementary teacher preparation programs in the United States require only one introduction course or none. Preparing to be an effective teacher for inclusive education requires a sound knowledge base along with direct classroom experiences working with students with exceptionalities. Yet, the results of this study showed that only $18 \%$ of the 220 NCATE accredited elementary teacher preparation programs in the United States clearly required any special education field hours/credits. Although inclusive education has doubled since the 1980's, the preparation of general education teachers to effectively teach in inclusive classrooms has not matched the needs that they will face in their classrooms. There is no evidence that the teacher preparation programs in the United States prepare general education teachers to take the responsibility of teaching ALL students regardless of the nature and severity of disability and educational need.

This study also addressed teacher perceptions of teaching in inclusive classrooms, to better understand if their teacher training and/or field experience has helped them to feel confident to manage the wider range of student abilities and needs. Results of the extensive literature review showed that even after 40 years of special education and 30 years with a focus that has increasingly served students with disabilities in general education settings, general education teachers still hold negative and mixed feelings (84\%) about teaching in inclusive classrooms. Teachers in the early decades expressed that they did not have sufficient training and resources available to provide effective inclusive education, and most modern studies disclosed that teachers universally face the 
same barriers for successful inclusive education. Considering only $23 \%$ of teacher preparation programs are requiring more than two special education courses or are offering elementary and special education combined majors and only $30 \%$ of these programs require some form of basic field experience, it is not surprising to see $84 \%$ of the recent studies (2000s to the present) found that teachers still had negative or mixed feelings about inclusive education. The inadequate training for teaching students with disabilities has been the number one concern of general education teachers. The alarming fact is that from the 1970's to 2014, teachers' positive perception on inclusive education has stayed below $20 \%$. Yet the feeling of empowerment to teach academic and functional curriculums to students with any academic abilities and learning deficiencies is the most critical factor for successful and efficient inclusive education. Thus, if general education teachers feel too much frustration regarding their effective teaching in inclusive classrooms, positive outcome of inclusive education cannot be expected (Kilanowski-Press, Foote, \& Rinaldo, 2010; Muccio, Kidd, White, \& Burns, 2014).

Educational effectiveness is the result of efficient teaching by highly competent and qualified teachers. With the limitations found in teacher preparation and weak teacher competence and supports regarding inclusion, the results of $82 \%$ of the studies on academics and $57 \%$ of studies on social outcomes with "no or mixed" gains are not surprising.

Considering all these intertwined results, is inclusion the answer? Perhaps the answer is "not yet." Given the findings on the limitations in teacher training programs to provide a strong background in knowledge and skills for working with students with disabilities, then, could an improvement (suggested by the self-reported data) in training programs nationwide for general education teachers better prepare them to teach the array of abilities of students within their classroom?

\section{Limitation of the Study}

As in all studies, there are a number of limitations the authors must disclose. First, this study was not able to review all teacher preparation programs offered in the United States, specifically those not accredited by NCATE. There may be different requirements in the programs accredited by the different authorities. Second, the results of teacher preparation status may not equally represent all 50 states because nine states had less than four universities/colleges in the NCATE list. Four states had only one university/college, another four states had two universities/colleges, and one state had only three programs in the NCATE list. Third, the information found regarding field experience requirements in the teacher preparation programs was dependent only on course descriptions. Thus, there may be more programs, which require special education field experiences but that information could not be found from online descriptions. Fourth, there was no pre-data available in the early stages of the inclusion movement to compare teacher preparation status. Fifth, the literature used in this study may be limited because only the ERIC database was used. There could be a larger number of studies found by using other search engines as well as by using different key words. Sixth, by limiting this study to information about inclusion in the United States, the study was not able to review as many studies as are 
available about the results of inclusive education especially for the academic and social outcomes. Many studies have been published in European countries, which the authors had to exclude from this study. Specifically, very rare studies have been conducted using empirical, experimental, and scientific research methods (standardized instruments), which can be critical for the efficacy testing studies of any particular program or policy, but could not be included in this study using professional literature about U.S. education. As Lindsay (2007) claimed, using more empirical study methods is important to provide a clear endorsement for the positive effects of the efficient inclusion. As a result, the final limitation of this study is that there is a lack of evidence from appropriate studies in the United States to conclude that there are positive social and academic outcomes of inclusive education.

\section{Conclusion}

The United States has established the expectation that ALL students will learn and have access to a free, appropriate public education. If the goal is to educate ALL students to the highest-level possible, and in the least restrictive environment, inclusion makes sense, but not as it exists presently, which ironically, was already addressed by opponents of rapid inclusion movements almost three decades ago when inclusion was initiated.

The research (Caspersen, Smeby, Olaf Aamodt, 2017; McHatton \& McCray, 2007; Schumm \& Vaughn, 1995) shows that in fact, the success of the academic and social skills for any student is dependent on their teachers' strong feelings of empowerment for teaching the curriculum for students of any ability and disability. According to Van Reusen, Shoho, and Barker (2000, p.13), teachers' limited learning and training opportunities produce lowered achievement for students, thereby further reinforcing teachers' negative attitudes or beliefs about inclusion. Pre-service cross training of general education and special education teachers is vital if inclusion is to be the answer. Thus, it is time to blend the skills of general education teachers who are adept at teaching content with the skills of special educators, who have been trained with specific skillsets to address the learning needs of students with disabilities. Many schools in the nation have already identified this need and are trying to support general education teachers with special education consultants. But even more importantly, it may well be time to cross train general education teachers with special education knowledge and experiences, just as special education teachers are required to have general education teaching certificates.

In addition, once teachers are in the field, the practice of co-teaching could bring more confidence and strategies into the successful teaching of all students in inclusive classrooms (DaFonte \& Barton-Arwood, 2017; Strongilos, Tragoulia, Avramidis, Voulagka, \& Papnikolaou, 2017). This practice is already occurring in many schools in the United States, especially secondary schools, where general and special educators work together in classrooms to address the individual needs of the students. If co-teaching strategies were added to preservice education courses, the skills and feeling of synergy and empowerment that could result from having two teachers plan and execute lessons might result in even greater success for students, both typically-achieving and those with disabilities. General and special education teachers need time to learn these new 
strategies and techniques and to keep abreast of new technology as they continue efforts to link the general education teachers' knowledge of curriculum with the special education teachers' knowledge of methods and materials for diverse learners.

Without preparing teaching personnel and pushing full inclusion for all school age students regardless of their ability, disability, personal uniqueness, and individual learning needs, we may be trying to provide 'equal' educational opportunities, but will also provide 'unfair' educational quality, resulting in inappropriate education to both groups of students. National special education data collection in the United States shows that teaching students in inclusive classrooms continues to grow as the preferred service delivery model. More research is needed to highlight the strengths and to build accountability into the practice of using this delivery model. This study showed the need for more research in the United States that scientifically measures the academic and social outcomes of inclusive education for students both with and without disabilities and to show what is and is not working in regards to the instruction to help all students to learn. This same type of scientifically-measured research is needed to compare the effectiveness of different inclusion models, the inclusive classroom's instructional environment, and behavior management and teacher effectiveness.

\section{References}

Ainscow, M. (1991). Effective schools for all. London: Fulton. https://doi.org/10.1080/02674649266780351.

Allday, R. A., Neilsen-Gatti, S., Hudson, T. M. (2013). Preparation for inclusion in teacher education pre-service curricula. Teacher Education and Special Education, 36(4), 298-311. https:/ / doi.org/10.1177/0888406413497485.

Cagran, B., \& Schmidt, M. (2011). Attitudes of Slovene teachers towards the inclusion of pupils with different types of special needs in primary school. Educational Studies, 37(2), 171-195. https://doi.org/10.1080/03055698.2010.506319.

Cameron, D. L., \& Cook, B. G. (2007). Attitudes of preservice teachers enrolled in an infusion preparation program regarding planning and accommodations for included students with mental retardation. Education and Training in Developmental Disabilities, 42(3), 353-363.

Caspersen, J., Smeby, J., \& Olaf Aamodt, P. (2017). Measuring learning outcomes. European Journal of Education, 52(1), 20-30. DOI: 10.1111/ejed.12205

Cronis, T. G., \& Ellis, D. N. (2001). Issues facing special educators in the new millennium. Education, 120(4), 639-649.

Da Fonte, M. A., \& Barton-Arwood, S. M. (2017). Collaboration of general and special education teachers: perspectives and strategies. Intervention in School and Clinic, 53(2), 99-106. https:/ / doi.org/10.1177/1053451217693370.

Dorn, S., Fuchs, D., \& Fuchs, L. S. (1996). A historical perspective on special education $\begin{array}{llll}\text { reform. Theory Into } \quad \text { Practice, } & \text { 35(1), }\end{array}$ https://doi.org/10.1080/00405849609543696.

Eitle, T. M. (2002). Special education or racial segregation: understanding variation in the representation of black students in educable mentally handicapped programs. The Sociological Quarterly, 43(4), 575-605. https:/ / doi.org/10.1525/tsq.2002.43.4.575. 
Farrell, P. (2000). The impact of research on developments in inclusive education. International Journal of Inclusive Education, 4, 153-162. https://doi.org/10.1080/136031100284867.

Ferri, B. A., \& Connor, D. J. (2005). Tools of exclusion: Race, disability, and (re)segregated education. Teachers College Record, 107(3), 453-474. https://doi.org/10.1111/j.1467-9620.2005.00483.x.

Fuchs, L.S., \& Fuchs, D. (1994). Inclusive schools movement and the radicalization of special education reform. Exceptional Children, 60, 294-309. https://doi.org/10.1177/001440299406000402.

Grider, J. R. (1995). Full inclusion: A practitioner's perspective. Focus on Autism and other Developmental Disabilities, $10(4), \quad 11$. https://doi.org/10.1177/108835769501000401.

Hartzell, R., Liaupsin, C., Gann, C., \& Clem, S. (2015). Increasing social engagement in an inclusive environment. Education and Training in Autism and Developmental Disabilities, 50(3), 264-277.

Harvey, M. W., Yssel, N., Bauserman, A. D., \& Merbler, J. B. (2010). An exploration of higher education teacher-training institutions. Remedial and Special Education, 31(1), 24-33.

Heward, W. L. (2012). Exceptional children: An introduction to special education. Englewood Cliffs, NJ: Merrill/Prentice Hall.

Hunt, P., Farron-Davis, F., Beckstead, S., Curtis, D., \& Goetz, L. (1994). Evaluating the effects of placement of students with severe disabilities in general education versus special classes. The Journal of the Association for Persons with Severe Handicaps, 19, 200-2014. https://doi.org/10.1177/154079699401900308.

Kauffman, J. M., \& Smucker, K. (1995). The legacies of placement: a brief history of placement options and issues with commentary on their evolution. In J. M. Kauffman, J. W. Lloyd, D. P. Hallahan, \& T. A. Assuto (Eds.), Issues in the educational placement of pupils with emotional or behavioral disorders (21-41). Hillsdale, NJ: Erlbaum.

Kilanowski-Press, L., Foote, C. J., \& Rinaldo, V. J. (2010). Inclusion classrooms and teachers: a survey of current practices. International Journal of Special Education, 25(3), 43-56.

Logan, B. E., \& Wimer, G. (2013). Tracing inclusion: determining teacher attitudes. Research in Higher Education Journal, 20, 1-10.

Mather, N., \& Robers, R. (1994). Learning disabilities: A field in danger of extinction? Learning Disabilities Research and Practice, 9(1), 49-58.

McCray, E., \& McHatton, P. (2011). "Less afraid to have them in my classroom": Understanding pre-service general educator's perceptions about inclusion. Teacher Education Quarterly. 38(4), 135-155.

McHatton, P. A., \& McCray, E. D. (2007). Inclination toward Inclusion: Perceptions of elementary and secondary education teacher candidates. Action in Teacher Education. 29(3), 25-32. https://doi.org/10.1080/01626620.2007.10463457.

Muccio, L. S., Kidd, J. K., White, C. S., \& Burns, M. S. (2013). Head start instructional professionals' inclusion perceptions and practices. Topics in Early Childhood Special Education, 34(1), 40-48. https://doi.org/10.1177/0271121413502398.

National Center for Education Statistics (2017). Retrieved from http://nces.ed.gov/programs/digest/d12/tables/dt12_050.asp.

Patton, J. M., \& Edgar, E. (2002). Introduction to the special series: special education and school reform. Remedial and Special Education, 23(4), 194. https://doi.org/10.1177/07419325020230040101.

Ross-Hill, R. (2009). Teacher attitude towards inclusion practices and special needs students. Journal of Research in Special Educational Needs, 9(3), 188-198. https://doi.org/10.1111/j.1471-3802.2009.01135.x. 
Ruijs, N. M., \& Peetsma, T. T. D. (2009). Effects of inclusion on students with and without special educational needs reviewed. Educational Research Review, 4, 6779. https://doi.org/10.1016/j.edurev.2009.02.002.

Schumm, J., \& Vaughn, S. (1995). Getting ready for inclusion: Is the stage set? Learning Disabilities Research and Practice, 10, 169-179.

Shogren, K. A., Gross, J. M. S., \& Forber-Pratt, A. J. (2015). The perspectives of students with and without disabilities on inclusive schools. Research and Practice for Persons with Severe Disabilities, 40(4), 243-260. https://doi.org/10.1177/1540796915583493.

Smith, T. E. C., Polloway, E. A., Patton, J. R., \& Dowdy, C. A. (2012). Teaching students with special needs in inclusive settings (2nd ed.). Boston: Allyn \& Bacon.

Strogilos, V., Tragoulia, E., Avramidis, E., Voulagka, A., \& Papnikolaou, V. (2017). Understanding the development of differentiated instruction for students with and without disabilities in co-taught classrooms. Journal of Disability $\mathcal{E}$ Society, 32(8),1216-1238.

http:/ / dx.doi.org.ezproxy.emich.edu/10.1080/09687599.2017.1352488.

Thompkins, R., \& Deloney, P. (1995). Inclusion: The pros and cons. Issues ... about Change, 4(3). Advancing Research, Improving Education. Retrieved from

U.S. Department of Education (1982). A nation at risk. Retrieved from $h$ ttp://datacenter.spps.org/uploads/sotw_a_nation_at_risk_1983.pdf.

Van Reusen, A. K., Shoho, A. R., \& Barker, K. S. (2000). High school teacher attitudes toward inclusion. The High School Journal, 84(2), 7-20.

Walther-Thomas, C., Bryant, M., \& Land, S. (1996). Planning for effective co-teaching: the key to successful inclusion. Remedial and Special Education, 17(4), 255-264. https:// doi.org/10.1177/074193259601700408.

Will, M. C. (1986). Educating children with learning problems: A shared responsibility. Exceptional Children, 52 https://doi.org/10.1177/001440298605200502. 